\title{
Fatal Outcome in a Right Bochdalek Hernia with Renal Ectopia Diagnosed in Adulthood
}

\author{
Israel Salgado Adame 1 (ㅇ), Alberto Manuel González Chávez ${ }^{2}$ (1), \\ Brisa del Mar Leslie Villanueva Bardales 1 (), Luis Roberto Jiménez Hernández ${ }^{3}$ (두 \\ ${ }^{1}$ General Surgery Department, Hospital Lic. Adolfo López Mateos I.S.S.S.T.E., Mexico City, Mexico \\ ${ }^{2}$ General Surgery Department, Hospital Español, Mexico City, Mexico \\ ${ }^{3}$ Cardiothoracic Surgery Department, Hospital Lic. Adolfo López Mateos I.S.S.S.T.E., Mexico City, Mexico \\ Email: salgadoadameisrael@gmail.com
}

How to cite this paper: Adame, I.S., Chávez, A.M.G., del Mar Leslie Villanueva Bardales, B. and Hernández, L.R.J. (2021) Fatal Outcome in a Right Bochdalek Hernia with Renal Ectopia Diagnosed in Adulthood. Open Journal of Thoracic Surgery, 11, 89-95. https://doi.org/10.4236/ojts.2021.114012

Received: July 26, 2021

Accepted: October 10, 2021

Published: October 13, 2021

Copyright (C) 2021 by author(s) and Scientific Research Publishing Inc. This work is licensed under the Creative Commons Attribution International License (CC BY 4.0).

http://creativecommons.org/licenses/by/4.0/

\begin{abstract}
Diaphragmatic hernias may be acquired or congenital. Among congenital hernias, the most common is Bochdalek hernia and eight out of ten Bochdalek hernias occur on the left side. They are usually diagnosed in the paediatric age group, and it is exceedingly rare for the diagnosis to be established in adulthood. Renal ectopy associated with a Bochdalek hernia is extremely rare, and very few cases are reported worldwide. We are reporting a case of a 73-year-old male patient with a right-sided Bochdalek hernia and renal ectopy. In this case, promp diagnosis and treatment could help to reduce the high risk of death in this kind of patients.
\end{abstract}

\section{Keywords}

Bochdalek, Renal Ectopia, Congenital Hernia, Diaphragm, Intrathoracic Kidney

\section{Introduction}

Diaphragmatic hernias occur because of a defect in the musculature of the diaphragm, which allows the passage of abdominal viscera into the thoracic cavity, causing restrictive pulmonary changes [1]. Diaphragmatic hernias are largely divided into two groups [2]:

- Congenital: anterior (Morgagni) and posterior (Bochdalek).

- Acquired or traumatic.

Congenital hernias occur in four out of every 10,000 live births, and they are usually diagnosed in the perinatal stage by ultrasound [1]. The most common type is the posterolateral or Bochdalek hernia (95\%); it occurs most commonly on the left side $(80 \%-85 \%)$ and contains the colon, stomach, omentum, and 
small intestine in the hernial sac [3]. In less than $1 \%$ of cases, the kidney may migrate through the diaphragmatic defect [4].

The main objective of this article is to present the case of an elder patient with a very rare congenital thoracic condition called Bochdalek's hernia which required emergency surgical thoracic approach in his adulthood and unfortunately, he died, hence to reduce the delay in the diagnosis and treatment of associated complications to this we are reporting this case.

\section{Case Presentation}

We present the case of a 73-year-old man, his past medical history included 10-year history of diabetes mellitus and hypertension under medical treatment and no history of thoracic or abdominal trauma, who came to the emergency room because of a 3-day history of generalized colic-type abdominal pain, inability to evacuate and pass gas, nausea, and vomiting with bloody streaks. Physical examination revealed decreased breath sounds at the base of the right lung, abdominal distension, and generalized pain on palpation, predominantly in the right upper quadrant. Vital signs are presented in Table 1. Lab tests upon admission are presented in Table 2.

Initial radiographs showed staggered effacement of the costodiaphragmatic angle, air-fluid levels, dilatation of the small bowel loops, and absence of gas in the rectal ampulla (Figure 1). With the diagnosis of intestinal occlusion, computed tomography with intravenous contrast of the abdomen was performed, which was extended to the thorax as part of the hospital's COVID-19 protocol; it showed a posterior defect in the right diaphragm (69 $\mathrm{mm}$ in diameter), through which protruded mesenteric fat, the right kidney (complete with renal vessels and proximal ureter), ascending colon, and cecum above the diaphragm (Figure 2) - which showed evidence of intestinal pneumatosis.

Table 1. Vital signs on presentation to hospital.

\begin{tabular}{cccc}
\hline \multirow{2}{*}{$\begin{array}{c}\text { Oxygen } \\
\text { saturation }\end{array}$} & \multicolumn{3}{c}{ Vital signs } \\
\cline { 2 - 4 } & Blood pressure (mm Hg) & Heart rate (bpm) & Temperature $\left({ }^{\circ} \mathrm{C}\right)$ \\
\hline $90 \%$ & $138 / 84$ & 110 & 37.3 \\
\hline
\end{tabular}

Table 2. Laboratory blood test results to admission.

\begin{tabular}{cc}
\hline Leukocytes & Laboratory Tests \\
& $15.4 \times 10^{6} \mu \mathrm{L}$ \\
\hline Neutrophils & $138 / 84$ \\
Platelets & $49.9 \%$ \\
Glucose & $345 \times 10^{3} \mu \mathrm{L}$ \\
Creatinine & $306 \mathrm{mg} / \mathrm{dL}$ \\
Lactate & $2.6 \%$ \\
\hline
\end{tabular}




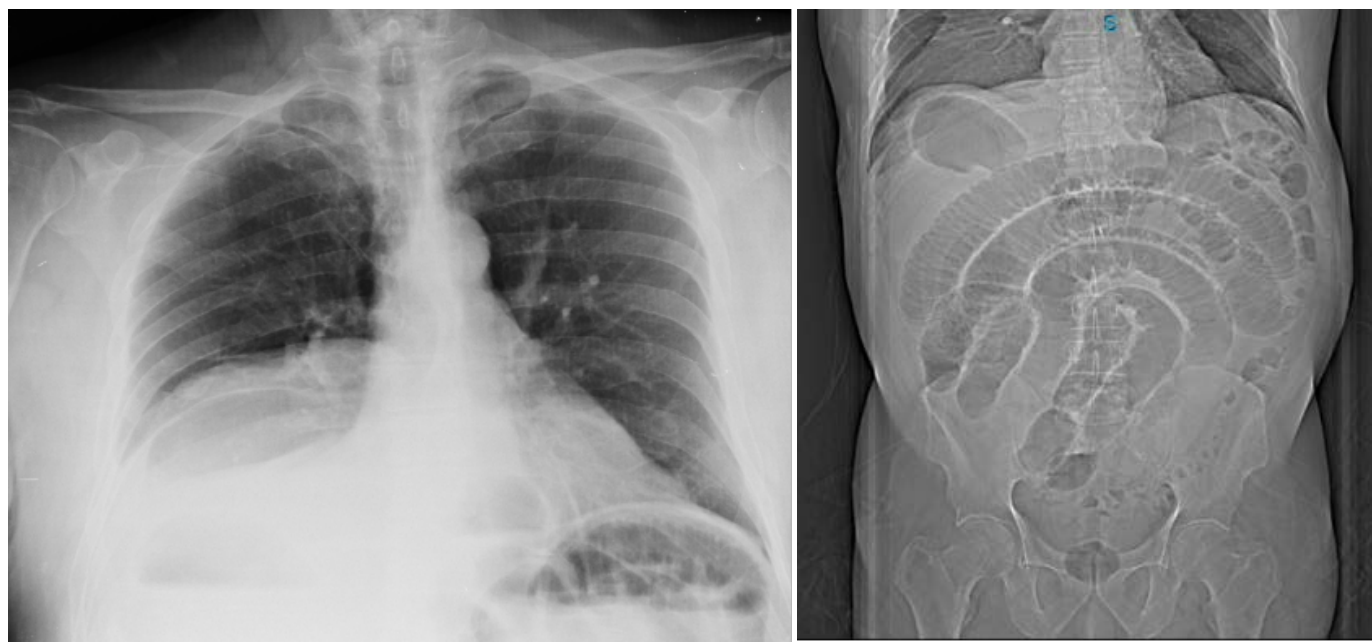

Figure 1. Chest X-ray with effacement of the costodiaphragmatic angle and Abdominal X-ray with significant dilation of the small bowel loops.

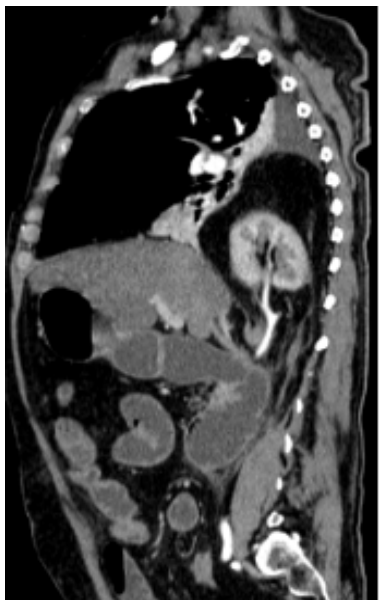

(a)

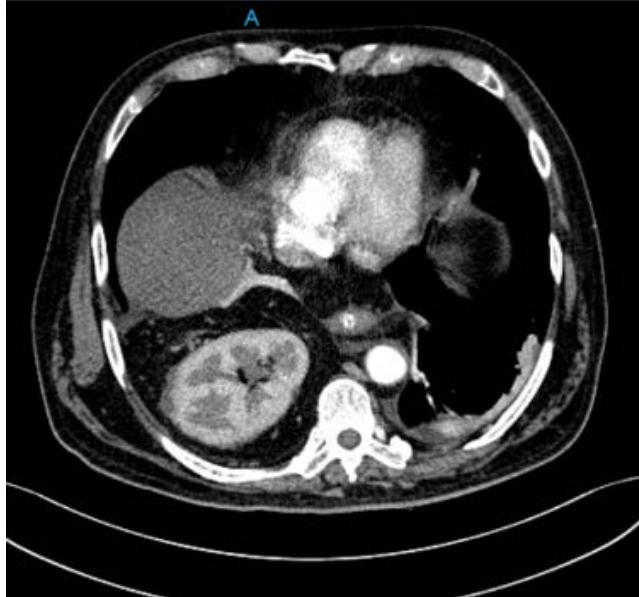

(b)

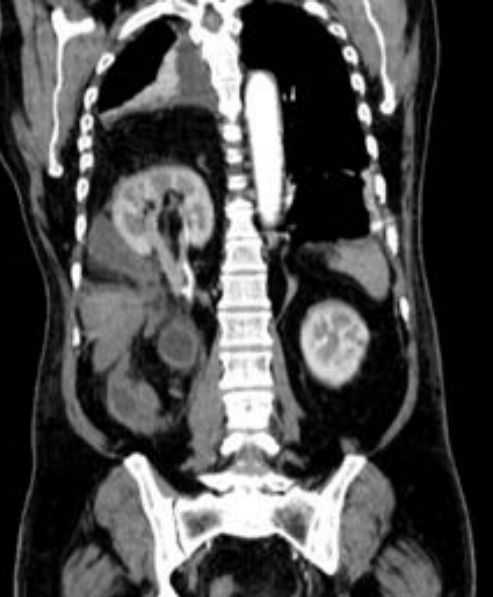

(c)

Figure 2. (a) Tomographic sagittal section with intravenous contrast showing the kidney and its pedicle within the thorax and above the diaphragm; (b) Axial tomographic section with intravenous contrast at the level of the cardiac chambers showing the right kidney within the right hemithorax; (c) Coronal tomographic section with intravenous contrast comparing the level of both kidneys; the right kidney seen above the liver and into the thorax.

It was decided to intervene surgically by performing a right posterolateral thoracotomy at the level of the fifth costal arch (Figure 3). When the hernial sac was opened, ischemic changes were observed in the small intestine $5 \mathrm{~cm}$ from the ileocecal valve; the same segment recovered its colour after releasing the adhesions and reducing the visceral content of the sac into the abdominal cavity. It was decided not to perform intestinal resection of the affected segment. A plasty of the diaphragm was performed to close the defect using Ethibond, and subsequently a $10 \times 15 \mathrm{~cm}$ polypropylene mesh was placed on the repaired diaphragm and fixed with Prolene sutures (Figure 4). A Jackson-Pratt type drain was placed in the abdominal cavity, and a $32 \mathrm{Fr}$ chest drain was placed in the right hemithorax.

During the reduction of the content of the hernial sac, the patient presented hemodynamic deterioration, for which vasopressors had to be administered. $\mathrm{He}$ 


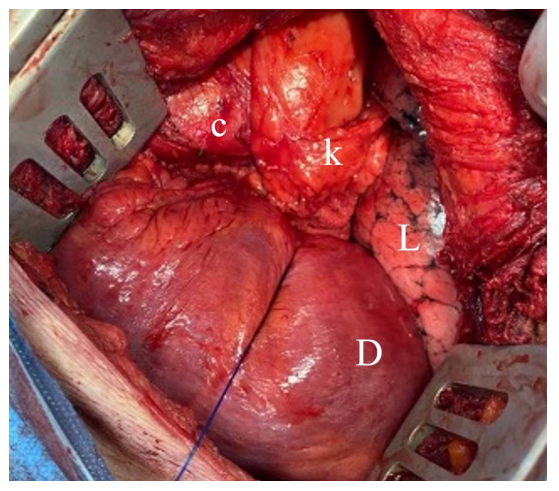

Figure 3. Intraoperative image of the posterolateral thoracotomy showing the cecum (c), right kidney (k), right lung (L) and diaphragmatic dome (D).

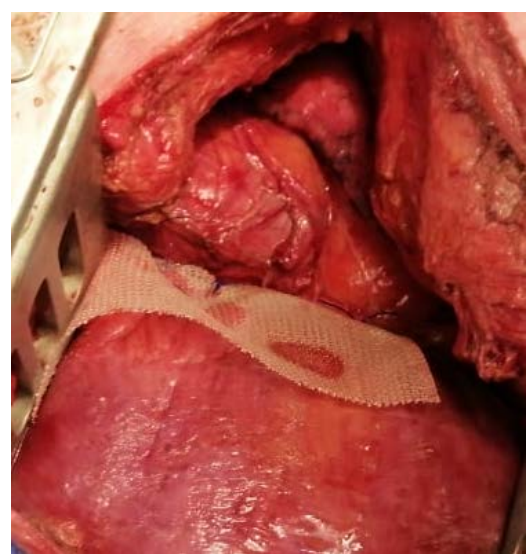

Figure 4. Intraoperative image of the thoracic space after cecum reduction into abdominal space with polypropylene mesh placed on the repaired diaphragm.

was discharged to the intensive care unit with ventilatory mechanical assistance and amine support. Patient progress was unfavourable; the peritoneal drainage presented purulent output, and leukocytes reached $21.8 \times 10^{3}$ per $\mathrm{mL}$ and creatinine $4.93 \mathrm{mg} / \mathrm{dL}$. The patient died on the fourth postoperative day owing to multiple organ failure secondary to sepsis.

\section{Discussion}

Vincent Alexander Bochdalek was the first to describe a congenital diaphragmatic hernia in 1848 [5]. Bochdalek hernia is the result of an inadequate development and fusion of the posterolateral portion of the diaphragm and of the lack of closure of the pleuroperitoneal membrane around the eighth gestation week. This hernia may occur in isolation or as part of a syndrome [2]. It is extremely rare for Bochdalek hernias to be diagnosed in adulthood [6]. In fact, there are less than 150 cases reported in the world literature, and of these, less than $20 \mathrm{pa}$ tients showed hernias on the right side [6] [7]. In adults, the most common manifestations are chronic dyspnoea, abdominal pain, postprandial fullness, vomiting, and pleural effusion. It may also become manifest with a pneumothorax or a strangulation of the visceral contents. The best method to diagnose it is contrast tomography [8]. 
A condition in which a kidney is out of its usual position is called renal ectopia. Intrathoracic renal ectopia represents less than $5 \%$ of all ectopia cases, and that associated with a congenital diaphragmatic hernia only accounts for $0.25 \%$ of the total cases [9]. According to the classification system proposed by Pfister-Goedeke and Burnier, there are four types of intrathoracic renal ectopia: 1) intrathoracic kidney with normal diaphragm, 2) intrathoracic kidney with eventration of the diaphragm, 3a) intrathoracic kidney with congenital diaphragmatic hernia or 3b) with acquired hernia, and 4) intrathoracic kidney with acute traumatic rupture of the diaphragm [10]. Intrathoracic kidney associated with a Bochdalek hernia can easily be reduced to its normal position, unlike the other types of intrathoracic renal ectopia. Usually, the kidney is located outside the pleural cavity; most need only be monitored because they remain asymptomatic and have a benign course.

In majority of individuals, the thoracic kidney is benign and asymptomatic. A incidentally detected intrathoracic kidney which is asymptomatic does not require any active intervention. Usually Bochdalek hernia is detected incidentally, but very rarely patients might present as an acute emergency due to the strangulation of herniated abdominal contents [8] [9]. Treatment is recommended when diaphragmatic hernia is accompanied by intestinal content, when there are complications in any of the hernia's contents (as in the present case), when the ureter is obstructed or there is vesicoureteral reflux [9] [11]. Some authors recommend, in addition to hernia repair, nephropexy [12] [13]. Hernia repair can be performed by the abdominal or thoracic route, by open surgery, by laparoscopy and even by a robot-assisted technique, using mixed approaches and hybrid procedures. An attempt should be made to close the defect because, otherwise, recurrence occurs in $14 \%-50 \%$ of cases [8] [13] [14] [15].

Naman Kohli's case report described a laparoscopic approach that at first was not successful due to the hernia sac could not be excised and the herniated content could not be reduced satisfactorily, it was necessary to perform thoracotomy to safely reduce the content to abdominal space [16]. There are also numerous cases in literature describing the primary VATS approach, especially in adults [17]. Kumar's case report mentions a combined approach (Laparotomy plus Thoracotomy) is preferred for the right sided Bochdalek hernia to facilitate the replacement of the herniated viscera and to close the diaphragmatic defect to overcome the mass effect of the liver [18].

\section{Conclusion}

We present the case of a fatal complication of an exceedingly rare type of hernia, a right Bochdalek hernia with a type 3a renal ectopia, diagnosed in a 73-year-old adult, in which it was decided to place a non-absorbable mesh, with high likelihood of infection as a complication of documented intestinal ischemia in the hernial sac, causing sepsis and multiple organ failure and finally the death of the patient. 


\section{Conflicts of Interest}

The authors declare no conflicts of interest regarding the publication of this paper.

\section{References}

[1] Keijzer, R. and Puri, P. (2010) Congenital Diaphragmatic Hernia. Seminars in Pediatric Surgery, 19, 180-185. https://doi.org/10.1053/j.sempedsurg.2010.03.001

[2] Chandrasekharan, P.K., Rawat, M., Madappa, R., Rothstein, D.H. and Lakshminrusimha, S. (2017) Congenital Diaphragmatic Hernia-A Review. Maternal Health, Neonatology and Perinatology, 3, 1-16. https://doi.org/10.1186/s40748-017-0045-1

[3] Puligandla, P.S., Skarsgard, E.D., Offringa, M., Adatia, I., Baird, R., Bailey, J.M., Traynor, M., et al. (2018) Diagnosis and Management of Congenital Diaphragmatic Hernia: A Clinical Practice Guideline. CMAJ, 190, E103-E112. https://doi.org/10.1503/cmaj.170206

[4] Keles, S., Artac, H., Elmaci, M., Reisli, I. and Dilsiz, A. (2006) Late-Presenting Congenital Diaphragmatic Hernia Associated with Ectopic Thoracic Kidney. European Journal of Pediatrics, 165, 571-572. https://doi.org/10.1007/s00431-006-0119-y

[5] Haller, J.A. (1986) Professor Bochdalek and His Hernia: Then and Now. In: Historical Aspects of Pediatric Surgery, Springer, Berlin, 252-255. https://doi.org/10.1007/978-3-642-70825-1_18

[6] Gedik, E., Tuncer, M.C., Onat, S., Avcl, A., Tacylldlz, I. and Bac, B. (2011) A Review of Morgagni and Bochdalek Hernias in Adults. Folia Morphologica, 70, 5-12.

[7] Salacin, S., Alper, B.E., Çekin, N. and Gülmen, M.K. (1994) Bochdalek Hernia in Adulthood: A Review and an Autopsy Case Report. Journal of Forensic Science, 39, 1112-1116. https://doi.org/10.1520/JFS13692J

[8] Brown, S.R., Horton, J.D., Trivette, E., Hofmann, L.J. and Johnson, J.M. (2011) Bochdalek Hernia in the Adult: Demographics, Presentation, and Surgical Management. Hernia, 15, 23-30. https://doi.org/10.1007/s10029-010-0699-3

[9] Murphy, J.J., Altit, G. and Zerhouni, S. (2012) The Intrathoracic Kidney: Should We Fix It? Journal of Pediatric Surgery, 47, 970-973. https://doi.org/10.1016/j.jpedsurg.2012.01.056

[10] Adam, A., De Villiers, M. and Van Biljon, G. (2013) Quest for the Missing Kidney in the "Treasure Chest": Report of a Thoracic Kidney in a Child with Recurrent Diaphragmatic Hernia. Urology, 82, 922-924. https://doi.org/10.1016/j.urology.2013.03.039

[11] Subramanian, V.S. and Goldfarb, D.A. (2008) Right-Sided Intrathoracic Renal Ectopia with Bochdalek's Hernia. Urology, 72, 1016-1017. https://doi.org/10.1016/j.urology.2008.05.012

[12] Yin, F., Wang, J., Gao, X. and Yi, L. (2021) Right Thoracic Ectopic Kidney with Congenital Diaphragmatic Hernia. Journal of Pediatric Surgery Case Reports, 71, Article ID: 101865. https://doi.org/10.1016/j.epsc.2021.101865

[13] Navaratnarajah, A., Barry, V. and Charif, R. (2020) Bochdalek Hernias Associated with Intrathoracic Kidney: A Case Report and Systematic Review of Outcomes Including Renal Function. Clinical Nephrology. Case Studies, 8, 1-11. https://doi.org/10.5414/CNCS109962

[14] Moro, K., Kawahara, M., Muneoka, Y., Sato, Y., Kitami, C., Makino, S., Nikkuni, K., et al. (2017) Right-Sided Bochdalek Hernia in an Elderly Adult: A Case Report with 
a Review of Surgical Management. Surgical Case Reports, 3, 1-6. https://doi.org/10.1186/s40792-017-0385-0

[15] Ohtsuka, Y. and Suzuki, T.H. (2017) Right-Sided Bochdalek Hernia in an Elderly Patient: A Case Review of Adult Bochdalek Hernias from 1982 to 2015 in Japan. Acute Medicine \& Surgery, 4, 209-212. https://doi.org/10.1002/ams2.249

[16] Kohli, N., Mitreski, G., Yap, C.H. and Leong, M. (2016) Massive Symptomatic RightSided Bochdalek Hernia in an Adult Man. BMJ Case Reports, 2016, bcr2016217432. https://doi.org/10.1136/bcr-2016-217432

[17] Tokumoto, N., Tanabe, K., Yamamoto, H., et al. (2010) Thoracoscopic-Assisted Repair of a Bochdalek Hernia in an Adult: A Case Report. Journal of Medical Case Reports, 4, 366. https://doi.org/10.1186/1752-1947-4-366

[18] Kumar, A., Maheshwari, V., Ramakrishnan, T.S. and Sahu, S. (2009) Caecal Perforation with Faecal Peritonitis-Unusual Presentation of Bochdalek Hernia in an Adult: A Case Report and Review of Literature. World Journal of Emergency Surgery, 4, 16. https://doi.org/10.1186/1749-7922-4-16 